\title{
MOTIVOS DA EVASÃO ESCOLAR NOS CURSOS DE ENSINO SUPERIOR DE UMA FACULDADE NA CIDADE DE BLUMENAU
}

Alexandre Luis Prim ${ }^{1}$ Jéferson Deleon Fávero ${ }^{2}$

RESUMO

A permanência do estudante na universidade está integrada e envolvida com o desenvolvimento social de toda a sociedade. Esta permanência vem sendo comprometida pela evasão do estudante que é foco nesta pesquisa. Este artigo tem como objetivo demonstrar e analisar a evasão de 42 estudantes de uma instituição de ensino superior em cursos tecnológicos no município de Blumenau/SC, no ano de 2012. A abordagem da pesquisa realizada é quantitativa, com delineamento descritivo, onde os dados foram coletados por meio da técnica de pesquisa documental. A população da pesquisa são todos os estudantes do ensino superior de uma faculdade particular da cidade de Blumenau. A amostra refere-se a todos os alunos evadidos no ano de 2012, sendo caracterizada como censo. Quanto aos resultados obtidos foram identificados que o maior percentual de evasão se enquadra no gênero masculino; que a faixa etária de 18 a 24 anos é a mais evadida; a maior parte dos alunos ingressam na IES pelo exame vestibular; a maior frequência de evasão acontece nos três primeiros semestres de curso; que o curso que evidencia maior evasão é o curso nomeado de "X" e que a maior causa de evasão é influenciada pela reprovação dos alunos. Portanto, este estudo voltado à cidade de Blumenau/SC demonstra um panorama relevante, sendo que a instituição de ensino superior pesquisada apresenta um percentual de evasão de aproximadamente $12 \%$, em que a média nacional aponta $22 \%$, dados estes que se referem à educação do ensino superior.
1. Especialista,e-mail: alexandrelprim@ gmail.com

2. Especialista, e-mail: hotmail.com jeferson_deleon@

Palavras-Chave: IES. Evasão no Ensino Superior. Universidade.

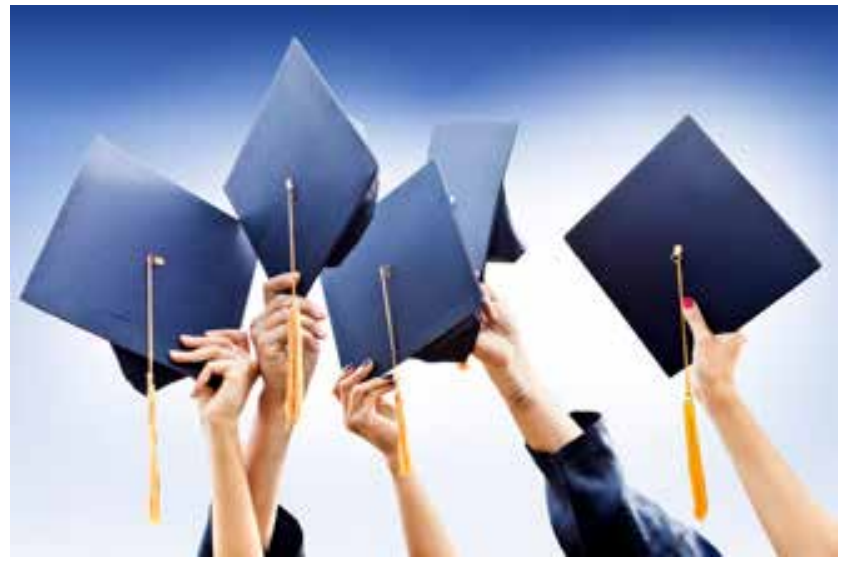




\section{INTRODUÇÃO}

Sabe-se que a educação no Brasil, assim como no mundo inteiro, é responsável por um altíssimo grau de importância para o desenvolvimento social, ou seja, traz sustentabilidade para uma sociedade que deseja evoluir de maneira intelectual, econômica, humana e estrutural.

Sobre as instituições universitárias do mundo contemporâneo entende-se que a evasão de estudantes é um fenômeno complexo, sendo influenciado por diversas variáveis, as quais despertam a necessidade de desenvolver estudos e análises sobre tal tema (MEC, 1996).

No entanto, segundo Braga, Peixoto e Bogutchi (2003) entende-se que o estudo sobre evasão do ensino superior brasileiro não tem uma expressiva e vasta área de interesse de pesquisa. A maioria dos estudos referente a este assunto foi desenvolvida a partir da década de 1980, os quais constituíram-se numa série de levantamentos, estudos de casos ou análises localizadas de alguns cursos, realizadas pelo Ministério da Educação e por universidades públicas.

Lobo (2012) corrobora com Silva Filho et al. (2007) indicando a evasão como um dos maiores problemas em qualquer nível de ensino, inclusive o ensino superior brasileiro, sendo ele público ou privado. Contudo, o abandono do aluno sem a conclusão de seus estudos acarreta em perda social, recursos e tempo de todos os envolvidos no processo de ensino de um País.

A evasão é um dos problemas que afligem as instituições de ensino superior (IES) em geral (SILVA FILHO et al., 2007). De acordo com o Ilda (2012) entre os anos 2004 e 2010 vem crescendo no Brasilo número de instituições do ensino superior, representando $18 \%$ de crescimento, o que vem destacar ansiedade em novas descobertas sobre os motivos de evasão.

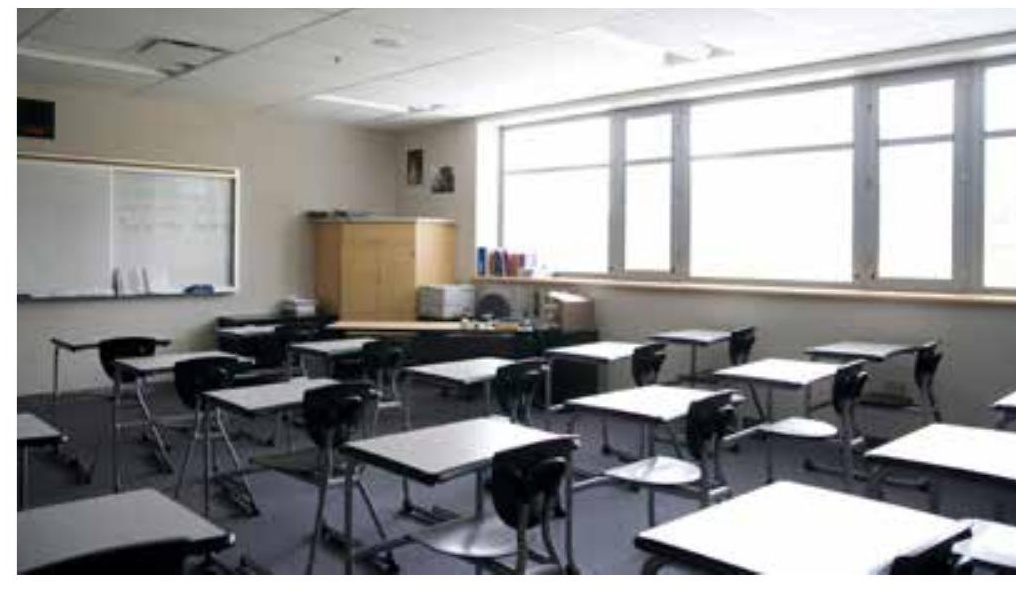

Entende-se que toda instituição de ensino superior (IES) tem a intenção de promover o melhor trabalho com os professores perante seus alunos. No entanto, a evasão nem sempre é influenciada por esses aspectos profissionais, pois a capacitação profissional não é unicamente função da educação superior (DIAS SOBRINHO, 2008). Oliveira (2009) fortalece Dias Sobrinho (2008) indicando que a educação superior está inserida num ambiente de adultos, ou seja, o professor tem o papel de ser o facilitador do conhecimento e cabe o aluno entender sua responsabilidade em sala de aula.

Muito se fala EM CONSTRUIR

A MOTIVAÇÃO DO ALUNO, POIS É UMA FORMA DE RETÊ-LO NA INSTITUIÇÃO, A fiM DE ORIENTAR, INCENTIVAR E FACILITAR A FORMAÇÃO, ENCAMINHANDO CIDADÃOS CONSCIENTES PARA A SOCIEDADE, ENTRETANTO ESSES ASPECTOS MOTIVACIONAIS DESTACAM-SE COMO UMA INCÓGNITA, VISTO QUE ESTUDAR, LER E PENSAR SÃO ATIVIDADES QUE NECESSITAM DE DEDICAÇÃO, DISCIPLINA E SACRIFÍCIO(OLIVEIRA, 2009). 
Quanto a contextualização da pesquisa sobre a temática de evasão no ensino superior, tem-se como problema de pesquisa a seguinte pergunta: Quais os motivos que influenciaram os alunos de uma instituição de ensino superior no município de Blumenau a evadirem no ano de 2012?

Em relação a estrutura da pesquisa apresentarse-á as considerações literárias e o confronto das posições de autores, com o objetivo de aprofundar e avaliar os conhecimentos teóricos mencionados. Nesse sentido, continua-se com a conceituação da educação no ensino superior, em seguida focaliza-se no tema específico da evasão no ensino superior.

Em um cenário sequencial apresentam-se os tipos de evasão que segundo o Ministério da Educação-MEC (1996), Biazus (2004) e Lobo (2012) acontecem de três formas: evasão do curso, da instituição e do sistema.MEC (1996) também identifica três fatores que ocasionam a evasão: fatores internos a instituições, externos as instituições e individuais dos alunos.

Identificam-se para Schargel e Smink (2002) sobre o fenômeno da evasão do ensino superior brasileiro categorias de causas da evasão que são mencionadas por psicológicas, sociológicas, organizacionais, interacionais e as econômicas.
Em sequência o MEC(1996) e Tigrinho(2008) fortalecem atividades a serem desempenhadas a fim de combater a evasão nas IES.

Demonstra-se que o estudo foi desenvolvido a partir de uma pesquisa quantitativa que para Richardson (1999) se caracteriza pelo emprego de quantificação tanto nas modalidades de coleta de informações documentais quanto no tratamento delas por meio de técnicas estatísticas e descritivas que têm como objetivo caracterizar determinada população ou fenômeno ou o estabelecimento de relações entre variáveis (GIL, 2009).

Sobre a amostra, a pesquisa abrange seis cursos tecnológicos no ano de 2012 em uma instituição de ensino superior de Blumenau/SC, considerada como um censo de pesquisa, pois foram averiguados todos os alunos que frequentaram a IES neste período.

Diante da análise de conteúdo sobre o tema demonstram-se os principais motivos de evasão do ensino superior de uma IES do município de Blumenau, bem como outros dados que servem de apoio ao entendimento do estudo.

Por fim, as considerações finais que são mencionadas com o intuito de providenciar operacionalização sobre as conclusões referenciadas na pesquisa realizada.

\section{EDUCAÇÃO NO ENSINO SUPERIOR}

Abordar-se-á neste capítulo as considerações literárias e o confronto das posições de autores, com o objetivo de aprofundar os conhecimentos teóricos gerando subsídios para o desenvolvimento da pesquisa.

O capitulo é dividido em duas partes. Iniciase com a conceituação da educação no ensino superior, em seguida focaliza a evasão no ensino superior.
Para iniciar o tema observe que a capacitação profissional segundo Dias Sobrinho (2008) indica que não é a única função da educação superior, mas também para a vida social.Oliveira (2009) corrobora com Dias Sobrinho (2008) indicando que a educação superior está inserida num ambiente de adultos. Indubitavelmente, o professor tem o papel de ser o facilitador do conhecimento. Todavia há alunos que não 


\begin{tabular}{|l|l|l|l|}
\hline Abrangência & $\begin{array}{l}\text { Atividades de pesquisa, ensino } \\
\text { e extensão }\end{array}$ & $\begin{array}{l}\text { Atividades de pesquisa, } \\
\text { ensino e extensão }\end{array}$ & Não há restrição \\
\hline $\begin{array}{l}\text { Cursos Stricto } \\
\text { Senso }\end{array}$ & $\begin{array}{l}\text { Mínimo de quatro programas } \\
\text { de pós-graduação recomen- } \\
\text { dado pela CAPES (havendo } \\
\text { no mínimo um curso de } \\
\text { doutorado) }\end{array}$ & Não há restrição & Não há restrição \\
\hline
\end{tabular}

Fonte: Brasil (2006)

Indubitavelmente existe diferenças entre IES com características peculiares. Portanto, Oliveira (2009) relata ser importante conhecer a realidade do ensino superior, como por exemplo, quantos cursos superiores, onde estão os alunos, em que áreas de estudo e pesquisa, o desempenho dos alunos entre outros.

\subsection{Evasão no ensino superior}

As maiores preocupações das instituições de ensino superior - IES, para o MEC (1996) são as de qualificar e garantir boa formação aos estudantes que forma para o exercício profissional.

A evasão no ensino superior é um problema que atinge até mesmo o cenário internacional, afetando os resultados dos sistemas educacionais, além disso,são desperdícios sociais, acadêmicos e econômicos (SILVA FILHO et al., 2007).

Para Costa (1991) a evasão conceitua-se como a saída do estudante da universidade ou de um de seus cursos, de maneira definitiva ou temporária, por qualquer motivo, financeiro, econômico ou social, exceto a diplomação. Souza (1999) corrobora com Costa (1991) adjetivando a evasão no ensino superior como uma problemática e ainda identificando fatores, tipos e causas da evasão.

No entanto, Lobo (2012) indica que o estudo da evasão deve ser adotado como uma política governamental geral voltada à qualidade acadêmica. Com os incentivos financeiros, a fim de desenvolver pesquisas e estudos que permitem mensurar com maior precisão, quais são as melhores práticas para combater com eficiência a problemática da evasão.

Neste sentido, para esclarecer o objeto de estudo, Bordas (1996), MEC (1996), Lobo (2012) classificam em três diferentes tipos de evasão, conforme se observa na figura 1: evasão do curso, da instituição e do sistema.

\section{Figura 1: Níveis de evasão}

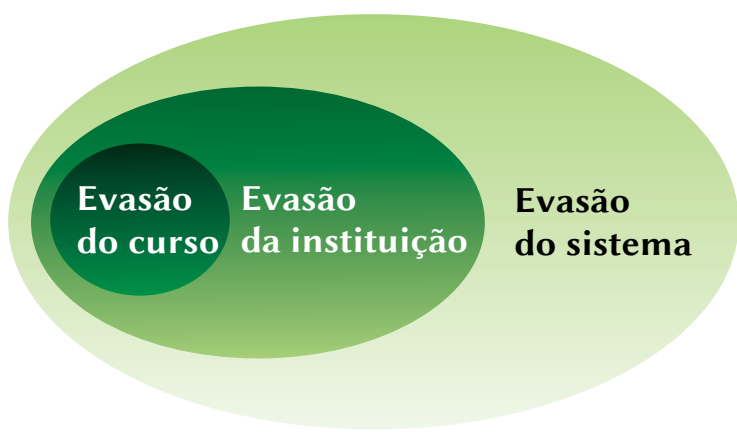

Fonte: Adaptado de Bordas (1996), MEC (1996) e Lobo (2012)

A evasão do curso, segundo MEC (1996) acontece quando o estudante desliga-se do curso de ensino superior por diversos motivos,como:abandono, desistência, transferência oure-opção e exclusão por norma institucional. Lobo (2012) e Biazus (2004) corroboram com MEC (1996) afirmando que esta evasão é aquela que o aluno muda de curso, mas permanece na mesma instituição de ensino. 
A evasão da instituição consiste no desligamento do estudante diante da instituição ao qual está matriculado (MEC, 1996). Lobo (2012) corrobora com MEC (1996) salientando que este tipo de evasão ocorre quando o estudante deixa a IES por outra, ou seja, muda de instituição.

Para MEC (1996) a evasÃo DO SISTEMA REPRESENTA O ABANDONO DEfINITIVO OU TEMPORÁRIO DO ESTUDANTE NO ENSINO SUPERIOR. NO ENTANTO, LOBO (2012)FORTALECE COM MEC (1996) COMPLEMENTANDO ESTE TIPO DE EVASÃO COMO AQUELA QUE O ESTUDANTE DEIXA DE ESTUDAR E ABANDONA O SISTEMA DE ENSINO, OU SEJA, NÃO ESTUDA EM NENHUMA OUTRA IES.

\subsubsection{Fatores e causas da evasão}

Para MEC (1996) há três fatores que influenciam a evasão ensino superior, conforme se apresenta na figura 2 .

Figura 2: Fatores que influenciam a evasão

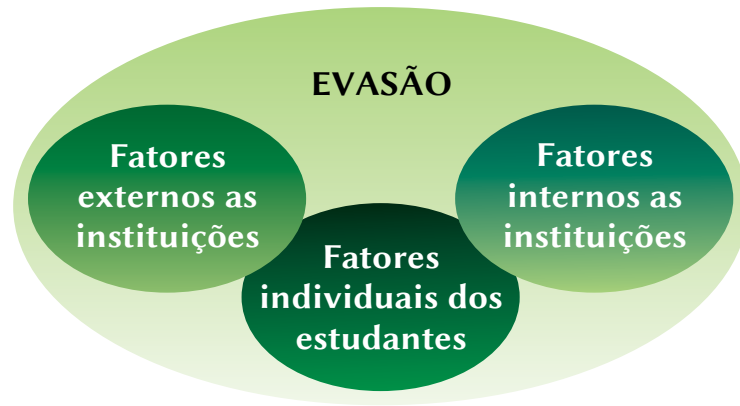

Fonte: Adaptado de MEC (1996)

Os fatores característicos individuais do estudante referente à evasão estão relacionados às habilidades de estudo, personalidade,formação escolar anterior, escolha precoce da profissão, dificuldades pessoais de adaptação à vida universitária, desencanto com o curso escolhido, dificuldades recorrentes de reprovações ou baixa frequência e desinformação a respeito da natureza dos cursos (MEC, 1996).

Já os fatores internos as instituições referentes à evasão, podem se caracterizar por questões peculiares a própria academia, a falta de clareza sobre o projeto pedagógico do curso, baixo nível de didática-pedagógica, cultura institucional de desvalorização da docência e estrutura insuficiente de apoio ao ensino (MEC, 1996).

Por fim, os fatores externos as instituições como o mercado de trabalho, reconhecimento social na carreira escolhida, conjuntura econômica, desvalorização da profissão, dificuldade de atualizar-se perante as evoluções tecnológicas, econômicas e sociais da contemporaneidade e políticas governamentais (MEC, 1996).

Braga, Peixoto e Bogutchi (2003) DESTACAM O ESTUDO DE EVASÃO NO ENSINO SUPERIOR BRASILEIRO COMO UM TEMA RELEVANTE, PORÉM DE PEQUENO INTERESSE EM PESQUISA. No ENTANTO, ATÉ O MOMENTO APRESENTAM-SE DOIS FATORES DISTINTOS DESTE FENÔMENO: A EVASÃO POR DECISÃO DO ALUNO OU POR CONSEQUÊNCIA DE UMA COMBINAÇÃO DE FATORES DA UNIVERSIDADE, SOCIOECONÔMICOS OU PESSOAIS, CONSIDERADOS MAIS COMO EXCLUSÃO DO QUE PROPRIAMENTE UMA EVASÃO. 
Lobo (2012) conclui que o problema da evasão deve ser discutido com todos os envolvidos na IES, das áreas acadêmicas e administrativo-financeiras, como gestores, professores, colaboradores e representantes de alunos, pois este combate não pode ser encarado apenas como uma gestão de marketing ou atendimento, mas fazer parte das ações estratégicas, com planejamento, execução, acompanhamento e avaliação.

Esta ação estratégica indicada por Lobo (2012) pode ser iniciada com a formação de uma equipe técnica, para estudar e acompanhar a evasão. Salienta ainda, a importância das informações, que devem ser confiáveis e organizadas, de forma setoriale global,com indicadores e metas, sendo respeitadas e alcançadas pelas IES.
No entanto, percebe-se que os principais problemas, não somente de evasão, como todos de uma IES, passam também pela sua gestão, pois não se pode ensinar um aluno sem comprometimento e com amadorismo. Necessita-se de comprometimento e profissionalismo, ou seja, a saída da zona de conforto de gestores, professores e também do próprio aluno, que deve exigir um ensino de qualidade (LOBO, 2012). Existem várias ponderações sobre o fenômeno da evasão do ensino superior brasileiro. $\mathrm{O}$ diagnóstico deste fenômeno divide-se em categorias de causas da evasão: as psicológicas, as sociológicas, as organizacionais, as interacionais e as econômicas (SCHARGEL; SMINK, 2002).

Apresentam-se no quadro 3 as cinco categorias que qualificam e exemplificam as causas:

Quadro 2: Categorias de causas da evasão

\begin{tabular}{|l|l|l|}
\hline Categorias & $\begin{array}{l}\text { Qualificações das } \\
\text { causas }\end{array}$ & Exemplos \\
\hline Psicológicas & $\begin{array}{l}\text { Comportamento do } \\
\text { indivíduo }\end{array}$ & $\begin{array}{l}\text { Reprovações sucessivas, falta de referencial familiar, } \\
\text { imaturidade e rebeldia }\end{array}$ \\
\hline Sociológicas & $\begin{array}{l}\text { Influenciado pelo meio } \\
\text { social }\end{array}$ & $\begin{array}{l}\text { Falta de orientação vocacional, deficiência da educação } \\
\text { básica, imposição familiar, casamento e filhos }\end{array}$ \\
\hline Organizacionais & $\begin{array}{l}\text { Influência da institui- } \\
\text { ção sobre o indivíduo }\end{array}$ & $\begin{array}{l}\text { Desconhecimento da metodologia do curso, concorrência } \\
\text { de outras IES, estrutura e corpo docente }\end{array}$ \\
\hline Interacionais & $\begin{array}{l}\text { Interação com colegia- } \\
\text { do e alunos }\end{array}$ & $\begin{array}{l}\text { Ausência de laços afetivos com a IES, mudança de ende- } \\
\text { reço, exclusão social e bullying }\end{array}$ \\
\hline Econômicas & $\begin{array}{l}\text { Relação } \\
\text { econômico-financeira }\end{array}$ & $\begin{array}{l}\text { Busca da herança profissional, falta de perspectiva pro- } \\
\text { e problemas financeiros }\end{array}$ \\
\hline
\end{tabular}

Fonte: Adaptado de Schargel e Smink (2002) e Gaioso (2005) 
Silva Filho et al., (2007) indica de forma geral que as principais causas da evasão estão relacionadas à situação econômico-financeira. Diante do quadro 3 supracitado entende-se que esta situação está relacionada à busca pela herança profissional, falta de perspectiva profissional, horário de trabalho incompatível com o horário de estudo, desemprego e problemas financeiros em geral. Da mesma forma é o que o próprio aluno declara como as principais causas.

Observe a seguir um resumo apresentado no quadro 4 referente aos principais motivos de evasão e abordagens dos autores relacionados a temática de evasão no ensino superior.

Quadro 3: Autores, abordagens e motivos de evasão

\begin{tabular}{|c|c|c|}
\hline Autor & Abordagem & Motivos \\
\hline Lobo (2012) & Abordagem no ensino público e privado & $\begin{array}{l}\text { Os principais problemas estão relacio- } \\
\text { nados a gestão universitária }\end{array}$ \\
\hline Oliveira (2009) & $\begin{array}{l}\text { Construir a motivação do aluno em virtude } \\
\text { da necessidade de retê-lo na instituição, a } \\
\text { fim de moldá-lo, orientá-lo, formá-lo, encami- } \\
\text { nhando cidadãos conscientes para a forma- } \\
\text { ção da sociedade }\end{array}$ & $\begin{array}{l}\text { As IES não conhecem o perfil de seu } \\
\text { aluno }\end{array}$ \\
\hline Tigrinho (2008) & $\begin{array}{l}\text { Abordagem no ensino público e privado } \\
\text { e formação de ações para combater o } \\
\text { fenômeno }\end{array}$ & $\begin{array}{l}\text { Os principais problemas estão rela- } \\
\text { cionados perante a gestão da IES com } \\
\text { poucas ações de combate a evasão }\end{array}$ \\
\hline $\begin{array}{l}\text { Dias Sobrinho } \\
(2008)\end{array}$ & $\begin{array}{l}\text { Preocupação com a responsabilidade social } \\
\text { do cidadão }\end{array}$ & Imaturidade dos estudantes \\
\hline $\begin{array}{l}\text { Silva Filho et } \\
\text { al. (2007) }\end{array}$ & Ambiente nacional e internacional & Econômico-financeira \\
\hline Costa (2005) & $\begin{array}{l}\text { Panorama da evasão no ensino superior } \\
\text { privado }\end{array}$ & $\begin{array}{l}\text { Quanto IES: infraestrutura, corpo docen- } \\
\text { te, matriz curricular } \\
\text { Quanto ao aluno: situação econômico- } \\
\text { financeira, incompatibilidade de horário } \\
\text { e desempenho do acadêmico }\end{array}$ \\
\hline Biazus (2004) & $\begin{array}{l}\text { Identificação dos principais indicadores de } \\
\text { influência à evasão dos cursos de ciências } \\
\text { contábeis da UFSM e UFSC }\end{array}$ & $\begin{array}{l}\text { Quanto IES: recursos humanos, didático } \\
\text {-pedagógicos e infraestrutura } \\
\text { Quanto ao aluno: aspectos socioeconô- } \\
\text { micos, vocação dos alunos e problemas } \\
\text { pessoais }\end{array}$ \\
\hline
\end{tabular}




\begin{tabular}{|l|l|l|}
\hline $\begin{array}{l}\text { Braga, Peixoto } \\
\text { e Bogutchi } \\
(2003)\end{array}$ & $\begin{array}{l}\text { Diagnóstico da evasão escolar de dezesseis } \\
\text { cursos superiores, envolvendo três grandes } \\
\text { áreas na UFMG }\end{array}$ & Fenômeno de causas variadas \\
\hline Schargel e & Conjunto de categorias influenciadoras & $\begin{array}{l}\text { Psicológicos, sociológicos, organizacio- } \\
\text { nais, interacionais e econômicos }\end{array}$ \\
\hline Souza (1999) & $\begin{array}{l}\text { Identificação dos índices de evasão de } \\
\text { cursos de graduação da UFSC no período } \\
\text { de 1996 e 1997 e as possíveis causas }\end{array}$ & $\begin{array}{l}\text { Acadêmico-institucionais, sócio-políti- } \\
\text { co-econômicos e pessoais }\end{array}$ \\
\hline MEC (1996) & $\begin{array}{l}\text { Orientação metodológica para determi- } \\
\text { nação das taxas de evasão, diplomação e } \\
\text { retenção }\end{array}$ & $\begin{array}{l}\text { Relacionados com o próprio estudante; } \\
\text { ao curso e à própria instituição e fatores } \\
\text { externos: sócio-culturais e econômicos }\end{array}$ \\
\hline Costa (1991) & $\begin{array}{l}\text { Estuda a evasão em diferentes cursos de } \\
\text { graduação da UFRGS de 1985 a 1987 }\end{array}$ & $\begin{array}{l}\text { Colisão de horário entre o curso e } \\
\text { profissão, insatisfação com o curso, } \\
\text { necessidade de trabalhar (situação } \\
\text { financeira) e exaustão para estudar }\end{array}$ \\
\hline
\end{tabular}

Fonte: Dos autores (2013)

Nota-se que em virtude das mais variadas percepções quanto a evasão do ensino superior os autores possuem posição próximas, ou seja, possuem convergência em opiniões e resultados.

Essas concentrações nas percepções quanto ao fenômeno relaciona-se a diversos fatores: a época em que as obras foram efetuadas pelos autores, a situação que a região oferecia ao pesquisador e a abrangência da pesquisa na sociedade. Tais objeções são percebidas em blocos em todos os autores. Identifica-se com tais características em um primeiro bloco, Lobo (2012) e Tigrinho (2008) que relacionam os principais problemas da evasão vinculados a gestão da IES. Diante do segundo bloco aponta-se Schargel e Smink (2002); Souza (1999); MEC (1996); Silva Filho et al. (2007); Costa (2005) e Braga, Peixoto e Bogutchi (2003) com percepções semelhantes expondo como principal fator os problemas econômicos e financeiros.

\subsubsection{Medidas de combate a evasão}

As medidas combatentes da evasão no ensino superior as IES possuem um papel importante através de políticas institucionais a fim de auxiliar os alunos a concluírem seus estudos (MELLO; SANTOS, 2012). Segundo MEC (1996) referente às políticas institucionais, salienta a importância do controle de ações para conter a evasão. Embora poucas IES possuem programas com dados e informações sistematizados que controlam o índice de evasão (TIGRINHO, 2008).

A partir deste pressuposto, MEC (1996) identifica algumas ações a fim de combater a evasão:

a) Realizar pesquisas com evadidos, buscando identificar as razões da evasão que os levam o abandono do curso superior;

b) Identificar as tendências mais recentes de evasão; 


\section{Raupp e Beuren (2009)}

RELATAM QUE A PESQUISA

DOCUMENTAL É NOTADA POR

REUNIR E ORGANIZAR DADOS

DISPERSOS, CONFERINDO-LHE

UMA NOVA IMPORTÂNCIA COMO

FONTE DE CONSULTA.

A população pesquisada foram todos os estudantes dos cursos superiores de tecnologia de uma IES de Blumenau/SC, tendo como amostra censo os alunos evadidos no ano de 2012.

Para efeito de cálculo sobre a evasão por curso realizou-se a identificação dos alunos evadidos do curso que não se diplomaram e não estão vinculados ao curso em questão. Porém, por limitações de dados, a fórmula foi adaptada a fim de mensurar com maior exatidão a representatividade de evasão no período em estudo.

Deste modo, o cálculo da evasão adaptado de MEC (1996) se expressa por:

\%Evasão $=\frac{\mathrm{Ne}}{\mathrm{Ni}} \cdot 100$
$\mathrm{Ni}-$ o número de ingressantes
$\mathrm{Ne}-$ o número de evadidos

Em relação ao objeto de estudo, foram levantadas informações junto à Coordenação do curso de ensino superior da instituição estudada sobre a quantidade de alunos evadidos ou desligados e seus respectivos motivos, os quais estão cadastrados em sistema informatizado, bem como a quantidade de alunos ingressos e diplomados no ano de 2012.

Foram coletados os dados pessoais, registros de matrícula e motivos causadores da evasão dos 42 alunos da instituição, dos 341 alunos matriculados, por meio do sistema SGN2. Em seguida se torna possível mensurar os dados e o percentual de evasão geral da instituição, bem como especificamente por curso. Da mesma forma, busca-se identificar as maiores causas influenciadoras da evasão na instituição, bem como analisar as variáveis quanto ao perfil do evadido, como gênero, empregabilidade, faixa etária e sob a vista das diferentes formas de ingresso, as quais se verificarão no tópico seguinte.

\section{ANÁLISE DOS DADOS E RESULTADOS}

Foram coletados os dados dos estudantes evadidos na IES estudada, com o objetivo de mensurar de forma precisa o problema da evasão, a qual será analisada a seguir.

Com o objetivo de conhecer o perfil dos alunos evadidos, buscaram-se variáveis como gênero, faixa etária, por tipo de ingresso, ou seja, como aconteceu o processo seletivo, o semestre e curso que os alunos mais alunos evadiram.

A partir das informações coletadas observe a tabela 1 o gênero dos evadidos da IES. 
Tabela 1: Gênero dos alunos evadidos

\begin{tabular}{l|c|c|c|c} 
Gênero & Matriculados & \% matriculados & Evadidos & $\%$ evadidos \\
\hline Masculino & 256 & $75,07 \%$ & 36 & $10,56 \%$ \\
\hline Feminino & 85 & $24,93 \%$ & 6 & $1,76 \%$ \\
\hline Total & 341 & $100,00 \%$ & 42 & $12,32 \%$ \\
\hline
\end{tabular}

Fonte: Dados IES pesquisada (2012)

Percebe-se que a pesquisa apresentou um maior percentual de evasão ao gênero masculino que obteve $10,56 \%$ dos alunos evadidos, justamente por representar aproximadamente $75 \%$ da contingência na IES.

Em termos de faixa etária, a tabela 2 apresenta seis classificações de alunos evadidos.

Tabela 2: Faixa etária dos alunos evadidos

\begin{tabular}{c|c|c|c|c}
\hline Faixa etária & Matriculados & \% matriculados & Evadidos & \% evadidos \\
\hline $18-24$ & 143 & $41,94 \%$ & 19 & $5,57 \%$ \\
\hline $25-31$ & 111 & $32,55 \%$ & 15 & $4,40 \%$ \\
\hline $32-38$ & 44 & $12,90 \%$ & 5 & $1,47 \%$ \\
\hline $39-45$ & 34 & $9,97 \%$ & 1 & $0,29 \%$ \\
\hline $46-52$ & 6 & $1,76 \%$ & 1 & $0,29 \%$ \\
\hline $53-64$ & 3 & $0,88 \%$ & 1 & $0,29 \%$ \\
\hline Total & 341 & $100,00 \%$ & 42 & $12,32 \%$ \\
\hline
\end{tabular}

Fonte: Dados IES pesquisada (2012)

De acordo com os dados da tabela 2 pode-se destacar quanto maior a faixa etária, menor o número de matriculados e consequentemente menor o número de evadidos. Cita-se comouma questão relevante a idade do acadêmico, pois quanto maior, aumenta seu nível de responsabilidade e compreensão sobre suas necessidades profissionais e sociais (SCHARGEL; SMINK, 2002; GAIOSO, 2005).

A evasão por modalidade de ingressos consiste identificar a representatividade dos evadidos versus matriculados de acordo com a forma de entrada na faculdade. 
Tabela 3: Alunos evadidos por modalidade de ingresso

\begin{tabular}{l|c|c|c|c}
\hline Processo seletivo & Matriculados & \% matriculados & Evadidos & $\%$ evadidos \\
\hline Exame vestibular & 267 & $78,30 \%$ & 25 & $7,33 \%$ \\
\hline Processo seletivo especial & 63 & $18,48 \%$ & 10 & $2,93 \%$ \\
\hline Regime especial & 6 & $1,76 \%$ & 6 & $1,76 \%$ \\
\hline Transferência de instituição & 5 & $1,47 \%$ & 1 & $0,29 \%$ \\
\hline Total & 341 & $100,00 \%$ & 42 & $12,32 \%$ \\
\hline
\end{tabular}

Fonte: Dados IES pesquisada (2012)

A evasão por tipo de processo seletivo, ou seja, a porta de ingresso ao curso indica maior percentual $(7,33 \%)$ por meio do exame vestibular, no entanto possui maior representatividade nos alunos matriculados (78,30\%). Não obstante, destaca-se também com uma representatividade razoável o processo seletivo especial $(18,48 \%)$, considerado como um tipo de processo seletivo da segunda chamada do exame vestibular, o qual responde por 2,93\% da evasão.O regime especial consiste na possibilidade do aluno matricular-se e realizar apenas disciplinas para conhecimento do curso, sendo considerado na análise como uma oportunidade de melhoria à instituição, ou seja,intensificar seus esforços estratégicos a fim de reter os alunos evadidos por esta categoria, pois todos os matriculados se evadiram. E, por fim, a transferência da instituição representa os alunos que trocaram de IES.

Devido à necessidade de entender quantos alunos se evadem em cada semestre apresenta-se na tabela 4 a representação.

Tabela 4: Evadidos por semestre de curso

\begin{tabular}{|c|c|c|c|}
\hline Semestre & Evadidos & $\%$ evadidos & $\%$ acumulado \\
\hline 2 & 19 & $5,57 \%$ & $45,24 \%$ \\
\hline 1 & 10 & $2,93 \%$ & $69,05 \%$ \\
\hline 3 & 5 & $1,47 \%$ & $80,95 \%$ \\
\hline 7 & 4 & $1,17 \%$ & $90,48 \%$ \\
\hline 5 & 2 & $0,59 \%$ & $95,24 \%$ \\
\hline 6 & 1 & $0,29 \%$ & $97,62 \%$ \\
\hline 4 & 1 & $0,29 \%$ & $100,00 \%$ \\
\hline Total & 42 & $12,32 \%$ & $100,00 \%$ \\
\hline
\end{tabular}

Fonte: Dados IES pesquisada (2012) 
De acordo com a tabela 4 percebem-se os três primeiros semestres com um maior percentual de evasão, representando aproximadamente $81 \%$ do total de evadidos. Momento que exige novamente da IES uma política de retenção, ou seja, desempenhar e desenvolver estratégia influenciadora ao discente(BRAGA; PEIXOTO; BOGUTCHI, 2003; LOBO, 2012). Uma proposta de estratégia pode estar vinculada a estudos que utilizam métodos quantitativos, os quais permitem identificar,perante investigação neste cenário, os aspectos com maior influência da IES sobre a permanência do aluno diante de sua qualidade, satisfação e lealdade(WALTER; TONTINI; DOMINGUES, 2005).

Com a intenção de verificar a evasão por curso demonstra-se na tabela 5 um levantamento da quantidade e representatividade de alunos evadidos. Com o anonimato da instituição, observa-se que os cursos estão explanados na tabela 5 abaixo com suas iniciais, a fim de não comprometer a IES.

Tabela 5: Evasão por curso

\begin{tabular}{c|c|c|c}
\hline Curso & Alunos evadidos & \% evasão & \% acumulado \\
\hline $\mathrm{Y}$ & 16 & $4,69 \%$ & $38,10 \%$ \\
\hline $\mathrm{Z}$ & 11 & $3,23 \%$ & $64,29 \%$ \\
\hline $\mathrm{T}$ & 7 & $2,05 \%$ & $80,95 \%$ \\
\hline $\mathrm{X}$ & 6 & $1,76 \%$ & $95,24 \%$ \\
\hline $\mathrm{V}$ & 1 & $0,29 \%$ & $97,62 \%$ \\
\hline $\mathrm{U}$ & 1 & $0,29 \%$ & $100,00 \%$ \\
\hline Total & 42 & $12,32 \%$ & $100,00 \%$ \\
\hline
\end{tabular}

Fonte: Dados IES pesquisada (2012)

De acordo com a tabela 5 destacam-se três cursos os quais somados correspondem aproximadamente $81 \%$ da evasão: o curso Y (4,69\%), o Z (3,23\%) e o T (2,05\%). Na construção de uma hipótese de evasão aprecia-se o estudo de Silva et al. (2012) que considera como fator responsável por este fenômeno a escolha do curso de maneira precipitada e equivocada pelo discente. Entretanto, nesta tabela a análise não representa o universo de alunos matriculados, por este motivo elaborou-se a tabela 6 , a qual compara a evasão de acordo com os discentes matriculados. 
Tabela 6: Comparação da quantidade de evadidos por curso

\begin{tabular}{c|c|c|c}
\hline Curso & Alunos evadidos & Alunos matriculados & $\%$ \\
\hline $\mathrm{X}$ & 6 & 23 & $26,09 \%$ \\
\hline $\mathrm{Y}$ & 16 & 78 & $20,51 \%$ \\
\hline $\mathrm{Z}$ & 11 & 90 & $12,22 \%$ \\
\hline $\mathrm{T}$ & 7 & 85 & $8,24 \%$ \\
\hline $\mathrm{V}$ & 1 & 15 & $6,67 \%$ \\
\hline $\mathrm{U}$ & 1 & 50 & $2,00 \%$ \\
\hline Total & 42 & 341 & $12,32 \%$ \\
\hline
\end{tabular}

Fonte: Dados IES pesquisada (2012)

De acordo com os dados apresentados na tabela 6 , sobre enfoque diferenciado da tabela 5 pode-se comparar utilizando a ponderação dos alunos matriculados, que por sua vez os cursos X (26,09\%), Y (20,51\%), e o Z (12,22\%) representam a maior evasão, pois a considera a partir do universo de alunos matriculados.
Posterior à identificação dos cursos com maior evasão, o estudo busca agora conhecer os motivos causadores da evasão que foram coletados da base de dados da IES pesquisada. Apresenta-se a tabela 7 , com suas respectivas quantidades e representatividades.

Tabela 7: Motivos de evasão da IES

\begin{tabular}{l|c|c}
\hline Motivos de evasão & Quantidade & $\%$ \\
\hline Reprovação & 10 & $23,81 \%$ \\
\hline Aluno em Regime especial & 6 & $14,29 \%$ \\
Problemas financeiros & 4 & $9,52 \%$ \\
\hline Inadimplência & 3 & $7,14 \%$ \\
\hline Mudança de curso & 3 & $7,14 \%$ \\
\hline Sem justificativa & 3 & $7,14 \%$ \\
Desmotivação com o curso & 2 & $4,76 \%$ \\
\hline Incompatibilidade de horário & 2 & $4,76 \%$ \\
\hline Mudança de cidade & 2 & $4,76 \%$ \\
\hline Problemas pessoais & 2 & $4,76 \%$ \\
\hline
\end{tabular}




\begin{tabular}{l|c|c}
\hline Desmotivação com o trajeto até a instituição & 1 & $2,38 \%$ \\
\hline Dificuldade de acompanhamento do curso & 1 & $2,38 \%$ \\
\hline Falecimento & 1 & $2,38 \%$ \\
\hline Transferência de instituição & 1 & $2,38 \%$ \\
\hline Problemas de saúde & 1 & $2,38 \%$ \\
\hline Total geral & 42 & $100,00 \%$ \\
\hline
\end{tabular}

Fonte: Dados IES pesquisada (2012)

De acordo com a tabela7 identifica-se que o maior motivo é a reprovação $(23,81 \%)$, notando-se que a evasão é resultante de uma exigência educacional da instituição. Em confronto com o estudo de Silva et al. (2012) outras evidências sobre a evasão foram encontradas nesta pesquisa, portanto Lobo (2012) afirma que um dos maiores problemas de evasão nas IES referem-se a reprovação.

Os motivos de problemas financeiros (9,52\%), inadimplência $(7,14 \%)$ e desmotivação com o trajeto até a IES (2,38\%) podem ser compreendidas como uma falta de planejamento e organização do estudante no início do curso. Ou seja,entende-se como uma ausência de previsibilidade. Contudo, também podem ser avaliados sob influências de alterações de emprego durante $o$ andamento do curso (SCHARGEL; SMINK, 2002).

A mudança (7,14\%), desmotivação com o curso $(4,76 \%)$ e dificuldade de acompanhamento do curso (2,38\%) identificam-se que ocorrem em função da falta de compreensão do aluno quanto aos objetivos do curso, algo que a instituição deve expressar preocupação e conhecimento
(LOBO, 2012), pois é neste momento que um teste vocacional, por exemplo, terá efeito de retenção desses alunos na IES.

A incompatibilidade de horário (4,76\%), mudança de cidade (4,76\%), problemas pessoais (4,76\%),falecimento (2,38\%), mudança de instituição (2,38\%) e problemas de saúde (2,38\%) são entendidos como motivos imprevisíveis, pelos quais o estudante inicia o curso sem a pretensão de que realmente aconteça ou o fato do evadido considerar o estudo como secundário (TIGRINHO, 2008).

A evasão sem justificativa obteve a representatividade de 7,14\% dos evadidos. Neste ponto, com este percentual a instituição deve absorver do estudante o máximo de informações, a fim de diagnosticar com maior precisão possível os reais motivos de sua saída.

A IES por permitir que alunos façam disciplinas em regime especial, obrigatoriamente ao final o discente matricula-se e realiza as demais disciplinas do curso ou opta pela evasão, correspondendo em 14,29\% da evasão, embora não foi analisado a retenção destes alunos. 


\section{CONSIDERAÇÕES FINAIS}

Este estudo analisou a evasão escolar de ensino superior em uma faculdade da cidade de Blumenau, no estado de Santa Catarina, bem como identificou o perfil dos evadidos e os motivos que influenciaram os alunos a tomarem esta decisão.

Primeiramente, parte-se da proposição de que nenhum aluno evadido recebia subsídio da instituição ou de algum outro programa governamental quanto a benefícios de bolsas estudantis. A IES estudada obteve 12,32\% de evasão no período de 2012, diferentemente do cenário brasileiro que apresenta cerca de $22 \%$ de evasão(LOBO, 2012). Portanto, destaca-se como uma diferença considerável, deixando a IES estudada num patamar de evasão inferior a média brasileira.

Todavia, pode-se afirmar que o perfil dos evadidos é do gênero masculino e representa aproximadamente $75 \%$ da amostra, possuindo faixa etária entre dezoito a trinta e um anos, correspondendo $74 \%$ dos matriculados e sendo ingressantes na maior proporção por meio do exame vestibular.

De segundo momento, foram analisados os semestres em que há maior índice de evasão. De fato, os três primeiros semestres juntos representam $80,95 \%$ dos evadidos, período que ocorre maior evasão (BRAGA; PEIXOTO; BOGUTCHI, 2003; LOBO, 2012).

As evasões ocorreram com maior frequência $(80,95 \%)$ nos cursos $\mathrm{Y}, \mathrm{Z}$ e T, considerando a evasão sobre a amostra (42 alunos), conforme tabela 5. No entanto, os cursos X (26,09\%), Y $(20,51 \%)$ e $Z(12,22 \%)$ possuem uma maior taxa de evasão, quando comparados à quantidade de alunos evadidos por matriculados. Este tipo de análise permite que as coordenações dos cursos possam elaborar estratégias, tomar atitudes, providenciar meios de contenção, a fim de diminuir o fenômeno (BRAGA; PEIXOTO; BOGUTCHI, 2003).

Os motivos mais relevantes da evasão correspondem a reprovação $(23,81 \%)$, problemas financeiros (9,52\%), inadimplência $(7,14 \%)$ e mudança de curso $(7,14 \%)$, somando um total de $47,61 \%$.

Neste sentido estes motivos são categorizados por Schargel e Smink (2002), por meio das causas psicológicas referentes aos motivos de reprovação, em seguida as causas econômicas em virtude dos problemas financeiros e inadimplência e por fim, as causas sociológicas que indica a mudança de curso influenciado pelo meio social.Portanto, quanto à reprovação, sugere-se que haja uma maior atenção institucional (direção, coordenação e professores) com os alunos que apresentam maiores dificuldades de aprendizagem no início do período letivo. Como exemplo, reforço de exercícios complementares(MEC, 1996).

Nos aspectos de problemas financeiros e inadimplência, sugere-se uma maior divulgação e orientação sobre os benefícios existentes aos alunos ingressantes, a fim de evitar uma evasão prematura do estudante do curso ou até mesmo da universidade, de maneira definitiva ou temporária como salienta Costa (1991).

Percebe-se uma carência no que tange aos testes vocacionais e entrevistas, o que para Oliveira (2009) é fundamental para nortear o aluno em sua linha de estudo. Por meio destes recursos seria possível identificar o perfil dos alunos ingressantes e orientá-los quanto às opções 
disponíveis de cursos. Nessa direção, Tigrinho (2008) contempla que os problemas de gestão das IES também são instrumentos que podem evitar evasões precoces.

Como limitação deste estudo, cita-se a ausência dos dados de períodos anteriores que direcionariam uma comparação longitudinal, assim como somente a utilização de documentos para compreender a dimensão da evasão na instituição.
Sugere-se para pesquisas futuras, entrevistar alunos evadidos para obter maior profundidade na compreensão da evasão. Assim como verificar o papel dos coordenadores dos cursos para reterem os alunos, visto que o poder de persuasão de um coordenador proporciona influência sobre o aluno por meio de suas experiências no ambiente educacional e profissional.

QS

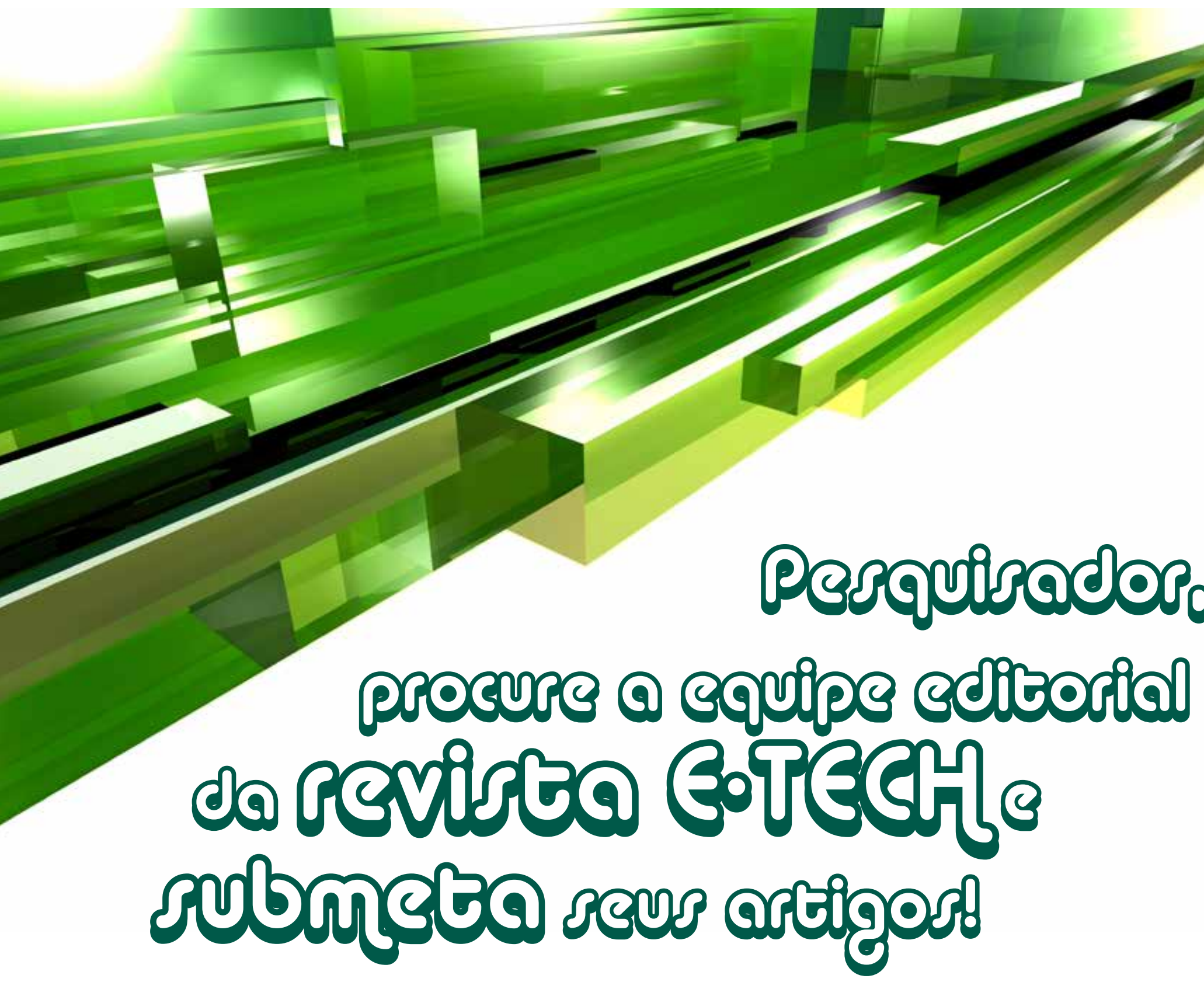

Revista E-TECH. TeCnologia para Competitividade Industrial.

FiesC. Federação da Industria do Estado de Santa Catarina. A Força da Indústria Catarinense. SENAI. Serviço Nacional de Aprendizagem Industrial. Uma Iniciativa da FiESC 


\section{CAUSES OF SCHOOL \\ EVASION IN HIGHER \\ EDUCATION COURSES OF A COLLEGE IN THE CITY OF BLUMENAU}

\begin{abstract}
The permanence of the student at the university is integrated and involved with the social development of the wholesociety. Thisattendance has been gradually being compromised by evasion a fact which is the focus of this research. This article aims to demonstrate and analyze the evasion of 42 students of an institution of higher education in technology courses in the city of Blumenau/SC, in 2012. The approach of the research is quantitative, with a descriptive outlining, where the data were collected by means of the technique of documentary research. The research population comprises all higher education students of a private college in the city of Blumenau. The sample refers to all dropout students in 2012, is characterized as census. As for the results obtained they were characterized by having the bighest percentage of evasion in males and in the age group of 18-24 years old; most students enter the IES college by entrance examination; the highestfrequency of evasion happens in the first three semesters of the course; the course that shows greater evasion is named " $X$ " and a major cause of evasion is the influence of academic failure of the students. Therefore this study, focused on the city of Blumenau/SC, shows a relevant panorama, and the highereducation institution studied shows a percentage of evasion of approximately $12 \%$, compared to the national average of $22 \%$ referring to data of teaching in higher education.
\end{abstract}

Key-words: IES. Evasion in

Higher Education. University

$* * *$

\section{REFERENCIAS}

BIAZUS, C. A. Sistema de fatores que influenciam o aluno a evadir-se dos cursos de graduação na UFSM e na UFSC: um estudo no curso de ciências contábeis. 2004. 203f. il. Tese (Doutorado em Engenharia de Produção) - Programa de pós-graduação em Engenharia de Produção, Universidade Federal de Santa Catarina, Florianópolis, 2004.

BORDAS, M. C. Diplomação, retenção e evasão nas universidades públicas brasileiras. In: FÓRUM NACIONAL DE PRÓ-REITORES DE GRADUAÇÃO DAS UNIVERSIDADES BRASILEIRAS, 10.,1996, Florianópolis. Anais... Florianópolis:UFSC, 1996.

BRAGA, M. M.; PEIXOTO, M. do C. L.; BOGUTCHI; T. F. A evasão no ensino superior brasileiro: o caso de UFMG. Avaliação: Revista de rede de avaliação institucional da educação superior. Campinas, v. 8, n. 3, p. 161-189, set. 2003.

BRASIL, Ministério da Educação. Qual é a diferença entre faculdades, centro universitários e universidades? [Brasília]: [2006]. Disponível em $<$ http://portal.mec.gov.br/index.php?option=com content\&view=article\&id=116:qual-e-a-diferencaentre-faculdades-centros-universitarios-euniversidades\&catid=127 >. Acesso em: 01 mai. 2013.

COSTA, A. L. da.Evasão dos cursos de graduação da UFRGS em 1985, 1986 e

1987. Porto Alegre: UFRGS, 1991.

COSTA, R. M. da. Evasão no ensino superior privado - como podemos evitá-la? ABMESeduca. com, 2005. Disponível em <http://abmeseduca. com/?p=3411 >. Acesso em: 17 abr. 2013.

DIAS SOBRINHO, J. Avaliação da educação superior: avanços e riscos. EccoS. São Paulo, v. 10, n. especial, p. 67-93, 2008.

GAIOSO, N. P. de L. O fenômeno da evasão escolar na educação superior no Brasil. 2005. 75 f. Dissertação (Mestrado em Educação) - Programa de Pós-Graduação em Educação da Universidade Católica de Brasília, Brasília, 2005.

GIL, A. C. Métodos e técnicas de pesquisa social. 6. ed. São Paulo: Atlas, 2009.

HAIR JR, J. F. et al. Fundamentos de métodos de pesquisa em administração. Porto Alegre: Bookman, 2005.

IIDA, A. M. F. (Org.). Números do Ensino Superior Privado no Brasil 2011: Ano base 2010. Brasília: ABMES Editora, 2012.

LOBO, M. B. de C. M. Panorama da evasão no ensino superior brasileiro: aspectos gerais das causas e soluções. ABMES Cadernos. Brasília, set./dez. 2012. 
MALHOTRA, N. Pesquisa de marketing: uma orientação aplicada. Porto Alegre: Bookman, 2006.

MEC. Diplomação, retenção e evasão nos cursos de graduação em instituições de ensino superior públicas. Avaliação: Revista de rede de avaliação institucional da educação superior. Campinas, v. 1, n. 2, p. 55-65, dez. 1996.

MELLO, S. P.T. de; SANTOS, E. G. dos. Diagnóstico e alternativas de contenção da evasão no curso de administração em uma universidade pública no sul do Brasil. Revista GUAL. Florianópolis, v. 5, n. 3, p.67-80, dez. 2012.

OLIVEIRA, F. B. de. Desafios da educação: contribuições estratégicas para o ensino superior. Rio de Janeiro: E-papers, 2009

RAUPP,F.M.; BEUREN, I. M. Metodologia da pesquisa aplicável às ciências sociais. In: BEUREN, Iise M. (org.). Como elaborar trabalhos monográficos em contabilidade: teoria e prática. 3. ed. São Paulo: Atlas, 2009.

RICHARDSON, R. J. et al. Pesquisa social: métodos e técnicas. 3.ed. São Paulo: Atlas, 1999.

SCHARGEL, F.P; SMINK, J. Estratégias para Auxiliar o Problema de Evasão Escolar. Rio de Janeiro: Dunya, 2002.

SILVA, F. I. C. da et al. Evasão Escolar no Curso de Educação Física da Universidade Federal do Piauí. Avaliação: Revista de rede de avaliação institucional da educação superior. Campinas, v. 17, n.2, p. 391-404,jul. 2012.

SILVA FILHO, R. L. L. et al. A evasão no ensino superior brasileiro. Cadernos de pesquisa. São Paulo, v. 37, n. 132, p.641-659, set./dez. 2007.

SOUZA, I. M. de. Causas da evasão nos cursos de graduação da Universidade Federal de Santa Catarina.1999.150f. Dissertação (Mestrado em Administração) - Programa de Pós-graduação em Administração, Centro Sócio-econômico, Universidade Federal de Santa Catarina, Florianópolis, 1999.

TIGRINHO, L. M. V. Evasão Escolar nas Instituições de Ensino Superior. Revista Gestão Universitária. São Paulo, 2008. Disponível em: < http://www. gestaouniversitaria.com.br/index.php?option=com_co ntent\&view=article\&id=649:evasao-escolar-nasinstituicoes-de-ensino-superior\&catid=135:173\&Item id=21 >. Acesso em: 04 mai. 2013.

WALTER, S. A.; TONTINI, G.; DOMINGUES, M.J.C. de S.Identificando oportunidades de melhoria em um curso superior através da análise dasatisfação dos alunos. In: ENCONTRO NACIONAL DE PROGRAMAS DE PÓS-GRADUAÇÃOEM ADMINISTRAÇÃO, 2005, Brasilia. Anais... Porto Alegre: Pallotti, 2005.

Data de recebimento: 08/09/13

Data de aprovação: 18/11/13

\section{SOBRE OS AUTORES}

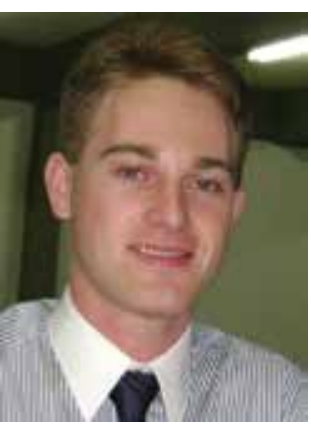

Alexandre Luis Prim

Tecnólogo em Produção

do Vestuário graduado pelo Serviço Nacional de Aprendizagem Industrial (SENAI) de Blumenau. Especialista em Gestão de projetos pela Faculdade de Administração e Economia (FAE) de Blumenau. Mestrando em Administração pela Universidade regional de Blumenau (FURB). Atuou em indústrias de transformação de grande porte no segmento têxtil e vestuário. Foi docente do curso de Tecnologia em Produção Têxtil e Tecnologia em Produção do Vestuário do SENAI Blumenau. Atualmente é consultor na mesma instituição, atuando nas áreas industrial-administrativas, com ênfase nos segmentos têxtil e vestuário.

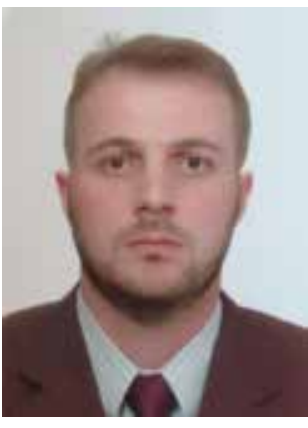

Jéferson Deleon Fávero

Administrador graduado pelo Centro Universitário Leonardo Da Vinci UNIASSELVI (UFSC) e Especialista em Gestão Financeira e Custos pelo Instituto Catarinense de Pós-Graduação (ICPG). Mestrando em Administração Universidade Regional de Blumenau pela FURB. Atuou como professor no curso técnico em logística no SENAI pelo Blumenau/SC. Atuou como policial militar no estado de Santa Catarina no setor de logística bélica na cidade de Blumenau. Foi docente do curso de Administração na Cetelbras Educacional. É coordenador de cursos no SENAI, Indaial, SC. 